\section{Rh Immunization}

SIR,-We are grateful to Dr. J. C. Woodrow for his comments (1 March, p 572) and readily agree with his statemen that mother-father ABO incompatibility does not inevitably result in mother-infant $A B O$ incompatibility. The homozygous states AA and BB represent only $20 \%$ and $5 \%$ of the phenotypically $A$ and $B$ individuals, respectively. As Dr. Woodrow has stated, approximately $42 \%$ of the infants born to the incompatible $\mathrm{A} \times \mathrm{O}, \mathrm{B} \times \mathrm{O}, \mathrm{A} \times \mathrm{B}, \mathrm{B} \times \mathrm{A}$ and $\mathrm{AB} \times \mathrm{A}$ or $\mathrm{B}$ mating combination will be ABO compatible.

In the three studies we reviewed (15 February, p. 399) selection pressures were observed consistently for the group $\mathrm{O}$ women but not for the non-group $\mathrm{O}$ women. The area of disagreement between Dr. Woodrow and ourselves therefore revolves about the interpretation of the extent of risk for, or conversely protection against, maternal $\mathrm{Rh}$ immunization for group $\mathrm{O}$ Rh-negativ women having $\mathrm{Rh}$ positive $\mathrm{ABO}$ incom patible infants.

The prospective Liverpool study, which includes observations of patients through subsequent $\mathrm{Rh}$-positive pregnancies cited by Dr. Woodrow, is the only accurate means for estimating the true incidence of maternal $\mathrm{Rh}$ immunization when dual (ABO and $\mathrm{Rh}$ ) incompatibility exists between mother and infant. In cases of dual incompatibility, the maternal anti-A and/or anti-B will reduce the mass of foetal antigen reaching the maternal spleen by sequestering the antigen in other organs. When the antigen mass is at the threshold level of immunization "sensibilization" or immunization without detectable antibody production becomes more common. In the study reported by Dr. J. C. Woodrow and Mr. W. T. A. Donohoe (19 October 1968, p. 139) and our study approximately $50 \%$ of the women immunized by $\mathrm{ABO}$ compatible $\mathrm{Rh}$-positive pregnancies had no detectable anti-Rh until restimulated by a subsequent $\mathrm{Rh}$-incompatible pregnancy. For the reason stated above one would anticipate the percentage of sensibilization would be even greater in $\mathrm{ABO}$ incompatibility.

The binomial confidence limits of the subsequent pregnancy data cited by Dr. Woodrow $(3 / 86)$ are $0.6 \%-10 \%$, which accommodates rather discordant intenpretations. It appears that our original estimate $(9-13 \%)$ of the risk of $\mathrm{Rh}$ immunization in group $\mathrm{O} R \mathrm{Rh}$ negative women having group $\mathbf{A}$ or $\mathbf{B} \mathrm{Rh}$ positive infants is too high and we wait with anticipation further experience by the Liverpool group which will enable them to answer this question.-We are, etc.

\section{William Q. Ascari.} Philip Levine. William Pollack.

Ortho Research Foundation New Jersey, U.S.A.

\section{Treatment of Angina Pectoris}

SIR,-Many will agree with the view expressed by Dr. D. Verel (10 May, p. 380) that " more evidence is needed before it can be accepted that coronary dilators such as trinitrin and prenylamine lactate do not act by dilating coronary arteries."
With regard to prenylamine lactate, however, it should be remembered that there is also strong experimental evidence that this preparation does also have an effect on the myocardial metabolism as evidenced in particular by its effect on catecholamine uptake and storage. ${ }^{12}$ It is our belief that these effeots may well be more important than the direct coronary dilating effect. Therefore it is probably misleading to classify prenylamine as a coronary dilator. Certainly it is incorrect to consider it together with trinitrin or other nitrate derivatives; neither does it have a specific beta-adrenergic blocking effect.

As more work is done it becomes increasingly clear that we are still a long way from understanding the exact mode of action of the anti-angina preparations, and this is just as true for the new beta-blockers with their seductively simple-sounding rationale as it is for the classical trinitrin. On the other hand, as a practical means of everyday treatment prenylamine lactate $60 \mathrm{mg}$. has been shown to be safe and effective for long-term maintenance therapy of angina pectoris. ${ }^{3-7}-\mathrm{I}$ am, etc.,

G. T. BASSIL.

Brentford, Middx. Divisional Director. Hoechst Pharmaceuticals.

\section{REFERENCES}

Mackenna, B. R., Acta Physiologica Scandinavica, $1965,63,413$.

Rielson, K. C., and Owman, C., Circulation Research, 1967, 21, 45

Cardoe, N., British fournal of Clinical Practice, 1968, 22, 299

1968, M., in Colloque de Monaco, March 1-2, $1968, \mathrm{pp}$ S3-65. 1968. Paris, Departemen tions et d'Informations.
Kappert, A. Zeitschrift für Therapie, 1965, 3, 82 .

Neumann, M., and Luisada, A. A., American fournal of the Medical Sciences, 1964, 247, 156.

Stoker, J. B., British fournal of Clinical Practice,

\section{Administration of Disodium Cromoglycate}

SIR,-Dr. H. Herxheimer and Miss Helga Bewersdorff (26 April, p. 220) have expressed doubts on the method of administration of disodium cromoglycate with the Spinhaler on the basis of their microscopic examination of the powder content of the capsules. Their concern, which may be shared by others, is understandable, since we are dealing with both a novel appliance and a unique compound which probably acts topically at the site of the antigen reaginic antibody interaction.

The drug, as presented in the capsule, consists of micronized disodium cromogylcate in size range providing more than $50 \%$ by weight between 2-6 $\mu$ (mass median diameter $2.6 \mu$, geometric standard deviation $1.4 \mu$, measured by the Coulter technique). The physical behaviour of such powders is dominated by surface forces (Van der Waal, electrostatic, adsorbed surface films, etc.) They are highly cohesive or "sticky" and become agglomerated into masses, with a lumpy appearance and poor flow properties. Since good flow properties are necessary for a powder to be dispensed from the Spinhaler the micronized disodium cromoglycate is mixed with lactose crystals in a size range of $30-60 \mu$ to improve the inadequate flow of the micronized drug alone.

The Spinhaler has two distinct actions : (a) the transfer of the powder from the capsule into the air stream, and $(b)$ the break- up and dispersion of the powder cloud into fine particulate matter suitable for inhalation. Inhalation through the device causes the capsule to spin and vibrate, so that the powder is ejected into the passing air stream. High-speed photography reveals that the powder is metered through the pierced holes of the capsule in the form of agglomerates, the transfer being accomplished by a complex mechanical action. ${ }^{1}$ The turbulent air streams inside the Spinhaler cause many agglomerates of drug and lactose to break up, and the resultant fine particles pass with the inhaled air into the respiratory tract. The remaining larger particles and agglomerates are, of course, retained in the upper airways. However, the locations in the lung where disodium cromoglycate is required to act have yet to be defined, so that the larger particles not necessarily capable of penetrating as far as the alveolar regions may in fact be necessary for therapeutic efficacy in some cases.

Urinary excretion studies in healthy volunteers have shown that about $9 \%$ of a $20-\mathrm{mg}$. dose inhaled from a Spinhaler is absorbed systemically in contrast to approximately $1 \%$ of an oral dose. ${ }^{2}$ Thus about $8 \%$ of the total dose can be assumed to have been absorbed from the respiratory tract.

We agree with Dr. Herxheimer and Miss Bewersdorff that disodium cromoglycate can be administered satisfactorily by an aqueous nebulizer, always provided that an adequate dose can be deposited in the appropriate area of the lung. Because of the low solubility (approximately 10\%) and high viscosity of the drug in water a power-operated nebulizer is necessary to deliver an adequate therapeutic dose. This method is therefore of limited use although it may be valuable for hospitalized patients. - We are, etc., J. S. G. Cox, Director of Research and Development. J. H. BELL. P. S. HARTLEY. Research and Development Laboratories. Fisons Pharmaceuticals Ltd.,
Leics.

Loughborough, Leics.

REFERENCES

1 Alexander, A. J., Downs, B., Mitchell, J. R., and Ward, G. F., Department of Mechanical Ennology, April 1968.

3 Cox, J. S. G., Disodium Cromoglycate Sympo-

\section{Rejection of Suture Material}

SIR,-It may be that a certain proportion of surgical wounds which break down and extrude stitches, with local reaction, are not in fact due to infection of the wound but to the patient's sensitivity to and intolerance of the suture material itself. Many surgeons have blamed themselves for the breakdown of wounds when the cause may have been outside their responsibility-and in the patient's own immune mechanism.

A doctor was seen recently who had undergone 12 surgical procedures. The first, an appendicectomy, was complicated by wound breakdown and the formation of a subphrenic abscess. Neither complication could be explained at the time. He next had a series of operations to remove the four menisci. The wounds of the first three of these operations all broke down between the fifth and 10th day with extrusion of stitches, sterile pus, and synovial sinus formation. London Hospital catgut had been used on each occa- 